\title{
Understanding variation in departmental adoption of Electronic Health Records: an embedded case study
}

Marjolein van Offenbeek ( $\nabla$ m.a.g.van.offenbeek@rug.nl )

Rijksuniversiteit Groningen https://orcid.org/0000-0002-5474-895X

Albert Boonstra

University of Groningen

Janita F.J. Vos

University of Groningen

Research article

Keywords: adoption, medical specialty, Electronic Health Record, implementation, work context

Posted Date: July 13th, 2020

DOI: https://doi.org/10.21203/rs.2.17193/v2

License: (c) (1) This work is licensed under a Creative Commons Attribution 4.0 International License.

Read Full License 
The authors have withdrawn this preprint from Research Square 